\title{
Validation of an instrument to determine oral health knowledge, attitudes, and practices during pregnancy
}

\author{
María de los Ángeles Ramírez-Trujillo ${ }^{1} \mathbb{0}$, María del Carmen Villanueva-Vilchis ${ }^{1 *}$ (D), \\ Fátima del Carmen Aguilar-Díaz ${ }^{1} \mathbb{B}$, Javier de la Fuente-Hernández ${ }^{1} \mathbb{B}$, Daniel Demétrio Faustino-Silva² ${ }^{\mathbb{B}}$ and \\ Luis Alberto Gaitán-Cepeda ${ }^{3}$ (1)
}

\begin{abstract}
Background: Oral health of the mother-infant dyad is important to preserve general health. However, there are few instruments in Spanish for the evaluation of knowledge, attitudes and practices that determine this construct. Therefore, this research aimed to develop and evaluate the psychometric properties of the Maternal Oral Health Knowledge, Attitudes and Practices Questionnaire (CAPSOM in Spanish).

Methods: In this instrument development study that carried out in 2018-2019, involving pregnant women between the ages of 18 and 45 in the city of Leon, Guanajuato, Mexico. The sample size was calculated based on 10 women per questionnaire item $(n=10 \mathrm{k})$. The study used Cronbach's alpha, the modified Lawshe test of validity criteria, factor analysis, and the level of difficulty and discrimination of the items.

Results: 207 women took part with their signed, informed consent ( $25 \pm 6$ years). The internal consistency of the instrument, both total and by dimension was $a=0.70, a=0.66$ knowledge, $a=0.74$ attitudes, and $a=0.66$ practices. Values of Content Validity Ratio' $\geq 0.60$ were obtained for the final 10 items and Content Validity Index $=0.90$. The average difficulty index of items was 0.40 , and there were significant differences (Kruskall-Wallis, $p<0.001$ ) in the discrimination test. Factor analysis demonstrated three main components.
\end{abstract}

Conclusions: A valid and reliable 10-item Spanish questionnaire was designed to measure pregnant women's oral health knowledge, attitudes, and practices.

Keywords: Validation study, Oral hygiene, Dental health surveys, Prenatal education, Pregnant women

\section{Background}

The wellbeing of the mother-infant dyad has a position of vital importance in public health, since it is a fundamental indicator of health and social inequalities [1]. A poor oral condition has direct implications on general

\footnotetext{
*Correspondence: cvillanueva@enes.unam.mx

${ }^{1}$ Department of Public Health, National School of Higher Studies, Leon Unit, National Autonomus University of Mexico (UNAM), Blvd. UNAM \#2011, Predio El Saucillo y El Potrero, Comunidad de los Tepetates, 37684 León, Guanajuato, México

Full list of author information is available at the end of the article
}

health. For example, it affects children's growth, ability to concentrate, hours of sleep, and even their socialization, in such a way that we must address all the factors related to that condition, including those related to the role and health of the mother [2]. On the other hand, there is a strong relationship between homeostasis, oral biofilm, and general health in such a way that during pregnancy periodontal disease might be considered as a risk factor for preterm birth, low birthweight, and preeclampsia [3]. During pregnancy, the mother and her child, face diverse health risks, so that 
the identification of the factors involved in the development of oral diseases, and the attendant preventive and prophylactic measures, are the first steps in oral health [4].

It is an established fact that mothers play a fundamental role as facilitators in achieving good oral health by their children. Thus, improvement in their knowledge and attitudes towards oral habits, will undoubtedly help improving the oral health of their children [4-7]. Therefore, the transmission of conducts and behaviors from mother to child has repercussions for the latter's oral health, specifically during the period of its first thousand days of life. For this reason, understanding the attitudes and knowledge on the subject of oral care, as well as determining the oral health practices of pregnant women, is important, as it will reveal their state of oral health during the course and conclusion of their pregnancies $[3,8,9]$.

Despite the importance of learning about and determining pregnant women's behaviors, and the fact that the last decade has seen the publication of information relating to oral self-care for expecting mothers, the instruments used for collecting this critical data are scarce. Some of the reports on the instruments available for the evaluation of oral health KAPs in pregnant women do not describe their psychometric characteristics, as many come from pilot tests with limited sample sizes [10-12]. On the other hand, several of the questionnaires designed for this purpose do not comprehensively assess knowledge, attitudes, and practices [13-18]. In addition, it is necessary to include some aspects related to cultural beliefs about oral health related to pregnancy that can be decisive for the wellbeing of the mother-child binomial and that are not addressed in most of the published instruments [19]. Given this, and with the aim of developing a tool for data collection that is valid, reliable and easily administered.

\section{Methods}

The aim of this research was to develop and evaluate the psychometric properties of the Maternal Oral Health Knowledge, Attitudes and Practices of pregnant women in the area of oral health: the CAPSOM (Conocimientos, actitudes y prácticas de salud oral materna).

The study was carried out in two phases: (1) Design and construction of the instrument to establish the knowledge, attitudes, and practices of pregnant women about oral health; and (2) validation of the instrument. The research protocol was approved by the Research Ethics Commission of the National School of Higher Studies
(ENES), Leon Unit, of the National Autonomous University of Mexico (UNAM) (CEI.18_013_S1).

\section{Phase 1: Design and construction of the CAPSOM instrument}

In preparation for the design of the instrument, two public health experts reviewed the scientific literature on and conceptual models of mother-child oral health [19-21], along with the recommendations contained in the pediatric guidelines issued by the American Academy of Pediatric Dentistry (AAPD) [22]. From the information collected, 20 questionnaire items were formulated in relation to oral health knowledge, attitudes, and practices regarding visits to the dentist, oral diseases during pregnancy, hygiene, calcium, and tooth loss.

\section{Face validity}

The 20 items were subjected to expert's face validity analysis, which resulted in the removal of seven items that were considered either repetitive or poorly constructed. This evaluation was made from the consensus of the two experts, submitting it to the evaluation of a third expert in pediatric dentistry to resolve the disagreements. The remaining 13 items were subjected to evaluation of face validity by the users on their order, grammar, clarity, and relevance through a pre-test involving five pregnant women attending a teaching clinic on pediatric dentistry (ENES-UNAM, León, Guanajuato, México). Based on the observations collected from the participants, linguistic-cultural adjustments were made to any items considered hard to understand.

Thus, the initial instrument consisted of 13 items split between 3 dimensions: (A) practices; (B) knowledge; and (C) attitudes.

\section{Phase 2: Validation and reliability of the instrument}

The cross-sectional study was carried out between October 2018 and April 2019. The study included pregnant women between 18 and 45 years of age attending prenatal checkups at three gynecological and obstetric care centers in the state social security system in the city of Leon, Guanajuato, Mexico. To be included in the study, the women had to be capable of answering the questionnaire by themselves. Those participants who did not complete the questionnaire and who voluntarily withdrew from the study were eliminated.

The sample size was calculated based on a minimum of ten women per questionnaire item in order to perform a factor analysis of an instrument consisting of 10 items 
$(n=10 \mathrm{k})$ [23]. The following demographic data were collected: age; educational level (from none to primary, secondary, high school or higher), occupation (homemaker, employee, professional, student, other), marital status (single, cohabiting, married, divorcee, widow).

\section{Data collection}

Once the modifications based on the pre-test were completed, and subsequent to a request for and receipt of informed consent, the participants were interviewed in the Education Room at the facilities of each of the centers included. Before filling out the questionnaire, they were given instructions on the procedure, stressing the privacy and confidentiality of the data and requesting that they provide sincere responses.

\section{Reliability (internal consistency)}

The Cronbach's alpha reliability coefficient was used to establish the internal consistency values for the instrument as a whole, by dimension and for each separate item.

\section{Content validity by experts}

Content validity by experts was established by using the modified Lawshe test [24]. Ten public oral health experts from five Latin American higher education institutions took part (the National Autonomous University of Mexico's National School of Higher Studies, Leon Unit, and its Dental School, the CES University of Medellín, Colombia, Chile's Andrés Bello University and the University of Sao Paulo, Brazil). Each item was classified as either "essential", "useful but not essential", or "not necessary". In addition, the Content Validity Ratio (CVR') was obtained for each item, this being defined as the proportion of essential agreements in relation to the total number of items. The acceptable value was set at $\geq 0.60$, in accordance with the recommendations of Tristán [24]. Finally, the Content Validity Index (CVI') of the entire instrument was calculated.

\section{Item difficulty index (D) and Item discrimination level (d)}

The quality of the items was established via a numerical expression of difficulty $(D)$ in which 0 indicated high difficulty and 1 low difficulty, with acceptable values falling between 0.20 and 0.80 . The item discrimination level $(d)$ evaluated the degree to which the question helped to increase the estimated differences between those which achieved a relatively high score on the test and those with a relatively low one. For this purpose, in order to compare the highest and lowest values, the tertile values for each dimension of the scale were obtained using the Kruskall Wallis test. The existence of a statistically significant difference was interpreted as good discrimination by the items $[25,26]$.

\section{Factor analysis}

In order to continue with the evaluation of construct validity, factor analysis was then performed. This verified the suitability of the sample respecting the correlation between the variables included by means of the Kaiser-Meyer-Olkin test and Bartlett's Sphericity test [27].

To extract the factors, the principal components method was employed and, in order verify the relation between these, the Varimax orthogonal rotation method was used. It was estimated that there was an adjusted factorial charges with the values $\geq 0.40$. Lastly a calculation was made of the variance explained by the solution [27].

\section{Results}

A total of 207 pregnant women with an average age of $25 \pm 6$ (in the 18-45 range) took part in the study. In terms of educational level, the most common was secondary, followed by high school. The occupation most

Table 1 Description of the population by sociodemographic characteristics. Leon, Guanajuato, Mexico, 2019. $(n=207)$

\begin{tabular}{lrl}
\hline Sociodemographic characteristic & $\mathbf{n}$ & $\mathbf{( \% )}$ \\
\hline Education & 7 & \\
None & 35 & 3.40 \\
Primary & 80 & 16.90 \\
Secondary & 49 & 38.60 \\
High school & 36 & 23.70 \\
Higher & 207 & 17.40 \\
Total & & 100 \\
Occupation & 132 & \\
Homemaker & 40 & 63.80 \\
Employee & 16 & 19.30 \\
Professional & 8 & 7.70 \\
Student & 11 & 3.90 \\
Other & 207 & 5.30 \\
Total & & 100 \\
Marital status & 42 & \\
Single & 84 & 20.20 \\
Cohabiting & 78 & 40.60 \\
Married & 3 & 37.70 \\
Divorcee/widow & 207 & 1.50 \\
Total & & 100 \\
\hline
\end{tabular}


Table 2 Content validity, difficulty, and discrimination per item on the CAPSOM. Leon, Guanajuato, Mexico, 2019. $(n=207)$

\begin{tabular}{|c|c|c|c|c|c|c|}
\hline Item & Dimension & Attribute & $\mathrm{CVR}^{\prime \mathrm{a}}$ & $A / R^{b}$ & $\mathrm{D}^{\mathrm{c}}$ & $d^{d}$ \\
\hline 1 & \multirow[t]{6}{*}{ Knowledge } & Issues with tooth decay and bleeding gums can get worse during pregnancy & 1 & A & 0.45 & \multirow[t]{4}{*}{$p<0.001$} \\
\hline 2 & & Gum problems can affect my pregnancy and create problems with my baby's birth & 0.9 & A & 0.72 & \\
\hline 3 & & It is inevitable to lose a tooth during pregnancy & 0.8 & A & 0.5 & \\
\hline 4 & & My baby's development will extract calcium from my teeth & 0.8 & A & 0.33 & \\
\hline- & & Teeth should be brushed one or more times a day during pregnancy & 0.5 & $\mathrm{R}$ & - & - \\
\hline- & & Going to the dentist during pregnancy poses a risk for my baby and me & 0.3 & $\mathrm{R}$ & -- & - \\
\hline 5 & \multirow[t]{3}{*}{ Attitudes } & $\begin{array}{l}\text { Hygiene measures are important to minimize any oral complications that may arise } \\
\text { during the pregnancy }\end{array}$ & 0.8 & A & 0.35 & \multirow[t]{3}{*}{$p<0.001$} \\
\hline 6 & & It is important to go to the dentist before, during and after the pregnancy & 0.9 & A & 0.36 & \\
\hline- & & It is very important to monitor your oral health during pregnancy & 0.4 & $\mathbf{R}$ & - & \\
\hline 7 & \multirow[t]{3}{*}{ Practices } & I brush my teeth twice or more times a day & 1 & A & 0.41 & \multirow[t]{3}{*}{$p<0.001$} \\
\hline 8 & & I use other methods of oral hygiene such as mouthwash, flossing, etc & 1 & A & 0.35 & \\
\hline 9 & & $\begin{array}{l}\text { I have received information from a dental professional about oral health care during my } \\
\text { pregnancy }\end{array}$ & 0.8 & A & 0.21 & \\
\hline \multirow[t]{2}{*}{10} & & I have visited a dentist during my pregnancy & 1 & A & 0.32 & \\
\hline & & & $\mathrm{CVI}^{\mathrm{e}} 0.90$ & & Total $D^{f} 0.40$ & \\
\hline
\end{tabular}

${ }^{a}$ CVR': content validity ratio for 10 experts (acceptable value $>0.60$ )

${ }^{\mathrm{b}} \mathrm{A} / \mathrm{R}$ : item accepted/item rejected according to the value obtained from the CVR'

${ }^{c} \mathrm{D}$ : difficulty index for the item (acceptable value 0.20 to 0.80 )

$\mathrm{d} d$ : discrimination level per item (Kruskal-Wallis, 0.05)

e CVI': Content Validity Index (acceptable value > 0.58)

${ }^{f}$ Total D: average difficulty index of the item (acceptable values close to optimum difficulty 0.50 )

frequently reported was homemaker, while the most common marital status was cohabiting (Table 1).

\section{Content validity by experts}

With regard to the CVR' (Table 2), values above 0.60 were obtained for 10 items. However, the statements, "Teeth should be brushed once or twice a day during pregnancy", "Going to the dentist during pregnancy poses a risk for my baby and for me", and "It is very important to monitor your oral health during pregnancy" received unacceptable values. Once these items were removed, the result was the final 10-item version of the CAPSOM, whose CVI' was 0.90 .

\section{Content validity}

The average difficulty index of the items was 0.40 . For the evaluation of the level of discrimination, a statistically significant difference (Kruskall Wallis, $p<0.001$ ) was observed in all the variables included, indicating that the items discriminated well (Table 2).

Analysis produced values appropriate for KMO of 0.66 and for Bartlett's Sphericity of $p<0.001$, demonstrating that they confirmed the assumptions regarding the administration of the test. The factor analysis revealed the existence of three dimensions: knowledge, attitudes, and practices, whose total explained variance was $57.11 \%$, this being the proportion of variance which the item scores can explain by means of the three factors identified.

Table 3 shows the loading factor on each dimension. The results show that factor one, which explains $25.10 \%$ of the variance, consists of items 7, 8, 9, and 10 in the practices dimension. Factor two explains $19.83 \%$ of the variance and contains the knowledge items 1, 2, 3, and 4. Lastly, factor 3 is composed of items 5 and 6, which correspond to the attitudes dimension, and explains $12.16 \%$ of the variance.

\section{Reliability (internal consistency)}

An analysis of internal consistency was performed which resulted in a total of 0.70 for ten items. Likewise, the Cronbach's Alpha value was analyzed for each dimension of the questionnaire, with resulting values of $\alpha=0.66$ for knowledge, $\alpha=0.74$ for attitudes, and $\alpha=0.66$ for practices (Table 4), denoting moderate to acceptable internal consistency values for each of the items. Additionally, this analysis guaranteed the continued inclusion of each of the items since it was possible to verify that the removal of none of them increased the alpha value concerning the total value of the instrument.

As a result of these analyses, the final version of the instrument consisted of ten items, with true/false responses for the four in the "knowledge" dimension, 
Table 3 Loading factor value of each questionnaire item in three components. Leon, Guanajuato, Mexico, 2019. (n=207)

\begin{tabular}{|c|c|c|c|}
\hline \multirow[t]{3}{*}{ Item } & \multicolumn{3}{|c|}{ Component } \\
\hline & 1 & 2 & 3 \\
\hline & Practices & Knowledge & Attitudes \\
\hline Issues with tooth decay and bleeding gums can get worse during pregnancy & - & 0.63 & - \\
\hline Gum problems can affect my pregnancy and create problems with my baby's birth & - & 0.76 & - \\
\hline It is inevitable to lose a tooth during pregnancy & - & 0.76 & - \\
\hline My baby's development will extract calcium from my teeth & - & 0.65 & - \\
\hline Hygiene measures are important to minimize any oral complications that may arise during the pregnancy & - & - & 0.85 \\
\hline It is important to go to the dentist before, during and after the pregnancy & - & - & 0.85 \\
\hline I brush my teeth twice or more times a day & 0.47 & - & - \\
\hline I use other methods of oral hygiene such as mouthwash, flossing, etc & 0.73 & - & - \\
\hline I have received information from a dental professional about oral health care during my pregnancy & 0.75 & - & - \\
\hline I have visited a dentist during my pregnancy & 0.75 & - & - \\
\hline \multicolumn{4}{|l|}{ Loading factor $>0.4$} \\
\hline Varimax rotation & & & \\
\hline
\end{tabular}

Table 4 Internal consistency per item on the CAPSOM. Leon, Guanajuato, Mexico, 2019. $(n=207)$

\begin{tabular}{lll}
\hline Dimension & $\begin{array}{l}\text { Cronbach's alpha if an item } \\
\text { is removed }\end{array}$ & $\begin{array}{l}\text { Cronbach's } \\
\text { alpha by } \\
\text { dimension }\end{array}$ \\
\hline Knowledge & 0.63 & 0.66 \\
& 0.54 & \\
& 0.53 & \\
& 0.62 & 0.74 \\
Attitudes & 0.59 & \\
& 0.59 & 0.66 \\
Practices & 0.65 & \\
& 0.62 & \\
& 0.54 & 0.70 \\
Total & 0.54 & \\
\hline
\end{tabular}

and a Likert scale (Completely disagree, Disagree, Neutral, Agree and Completely agree) for the six remaining items corresponding to the "attitudes" and "practices" dimensions. Appendix 1. Thus, the minimum score on the instrument is 0 and the maximum 28, and the higher the score, the greater the levels of knowledge, attitudes, and practices.

\section{Discussion}

This project designed and validated an instrument to determine the pregnant women's knowledge, attitudes, and practices regarding oral health during their pregnancies with the aim of creating a reliable and useful tool for the collection of data that would provide valuable information for the study of the oral health of the mother-child dyad, and ultimately establish strategies and plans for improving perinatal oral health, for both mothers and their newborn babies. The study of knowledge on dentistry for newborns has acquired enormous importance in recent decades. The development of this instrument took into account the various approaches to education on babies' dental health, resulting in the inclusion of items related to mothers' knowledge and perception of oral diseases during pregnancy, oral hygiene measures, tooth loss, calcium loss and the possible risks involved in attending dental appointments during pregnancy [28-31].

Concerning reliability, the minimum values obtained were 0.66 for Cronbach's alpha in the dimensions of knowledge and practices. It has been suggested that, in newly developed instruments, values higher than 0.60 should be considered acceptable [32, 33]. For this reason, the values that we obtained for the entire questionnaire, as well as for each of the dimensions, are indicative of strong internal consistency.

With regard to content validity, it was decided that the evaluations carried out by the panel of experts should be done individually, and evidently in different physical spaces, thus avoiding any influence by the opinions of others, as happens with the Nominal Group Technique [34]. The inclusion of experts from various fields of expertise-e.g., university academics, clinicians, public health experts, pediatric dentists, experts in motherinfant interventions, and an expert in dentistry for babies-strengthened the constructs. 
The Lawshe test, as modified by Tristán in 2008, was utilized as it makes it possible to make both an estimate of validity per item (CVR') and an estimate for the instrument as a whole (CVI') [24], as opposed to the method proposed by Delphi [35], which requires the participation of a larger number of experts and is more time-consuming, thereby resulting in a high number of withdrawals. Additionally, the modified Lawshe test makes it possible to obtain cutoff points according to the number of panelists, thereby facilitating the interpretation of the values. The wide range of differences between the experts can lead to difficulties in reaching a consensus [33, 36]. Therefore, given their acceptable CVR' values, we believe that the items on the proposed instrument are sufficiently robust to measure the construct.

Regarding content validity, for this project, it was decided to include- prior to the factor analysis - an evaluation of the quality of the items by means of the index of difficulty and level of discrimination commonly used in education $[33,37]$. In the instrument proposed here, the average difficulty index per item was found to be 0.40 , a value close to optimum difficulty (0.50). Currently, these indices are introduced into the health context when dealing with constructs such as knowledge and attitude [38]. These tests verify whether the complexity of the item describes the level of cognitive ability required to obtain a correct answer. This fact has great importance for our population, since in Mexico the educational level most common among the population $\geq 15$ years of age is secondary school.

Regarding discrimination, this questionnaire enables correct identification of those cases with different levels of KAP. Factor analysis results indicated the presence of at least one correlation between two items, demonstrating the feasibility of factorization. The resulting factorial matrix groups the items in three dimensions: knowledge, attitudes, and practices, just as had been proposed.

In comparison with other instruments, some of them are focused on the evaluation of KAPs during pregnancy, have been created in English [13-16], Spanish [14, 15] and Kannada [11, 12, 17] and have been used in countries such as India [11, 12, 17], Australia [18], the United States [14, 15], Latin American countries [39-41] and in some regions of Asia [10]. Despite being widely used, the domains on which the questions are conducted vary in an important way. There are studies in which only knowledge has been included, some others in conjunction with attitudes and few with the inclusion of the complete KAP elements. In addition, in the description of the analysis and the properties of the instruments, almost none of the existing instruments show validity and reliability values. Only the questionnaire used by Gupta [11], reports very similar Cronbach's alpha and Keiser-Meyer-Olkin values to the present study. However, it should be mentioned that our instrument contains fewer questions, which is considered an advantage in terms of its application.

On the other hand, while the purpose of Gupta's questionnaire [11] is to compare pregnant and non-pregnant women, our instrument is complemented with the use of a questionnaire on infant oral health, which provides a broader landscape in the study of maternal and infant oral health.

This work does have some limitations. First of all, it was not possible to evaluate the stability over time of the instrument. Participants were approached to evaluate the consistency of the questionnaire when they attended educational talks in the pregnant women's club, prior to starting a maternal and child oral health program, so that once exposed to the educational sessions, it was impossible to avoid having changes in KAP. This situation essentially modified the purpose of the retest, which is to evaluate the variation from the instrument due to the effect of time when it is applied a second time under the same conditions.

Another limitation has to do with the conditions under which we had to work with the pregnant women which made it not feasible to have clinical evaluations, resulting in the impossibility to verify the validity of the criteria; it means the ability of the instrument to discriminate between the observed oral health conditions according to the variation of the instrument.

The CAPSOM questionnaire was validated in the case of Mexican women, however, with the suitable prior cultural adjustments-as pregnancy carries a significant symbolic load, we would suggest that its administration be extended to other Spanish-speaking populations. The adjustments made for each region will make it possible to improve the collection of data from each target population.

\section{Conclusions}

The study resulted in a 10 -item, self-answer questionnaire in Spanish that is valid and reliable to assess pregnant women's oral health knowledge, attitudes, and practices, thereby contributing a valuable instrument for mother-infant wellbeing, which continues to be a priority in the area of health. 


\section{Appendix}

Oral Health Knowledge, Attitudes, and Practices During Pregnancy

Code:

\section{Instructions}

Please read each question carefully and place in the box option that most closely matches your opinion.

I know that...

1. Issues with tooth decay and bleeding gums can get worse during pregnancy
0) False
1) True

2. Gum problems can affect my pregnancy and create problems with my baby's birth
0) False
1) True

3. It is inevitable to lose a tooth during pregnancy
0) False
1) True

4. My baby's development will extract calcium from my teeth

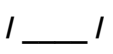
0) False
1) True

I consider that...

5. Hygiene measures are important to minimize any oral complications that may arise during pregnancy
0) Strongly Disagree
1) Disagree
2) Neutral
3) Agree
4) Strongly Agree

6. It is important to go to the dentist before, during and after pregnancy
0) Strongly Disagree
1) Disagree
2) Neutral
3) Agree
4) Strongly Agree

Regarding my oral health...

7. I brush my teeth twice or more times a day

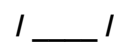
0) Strongly Disagree
1) Disagree
2) Neutral
3) Agree
4) Strongly Agree

8. I use other methods of oral hyigiene such as mouthwash, flossing, etc.
0) Strongly Disagree
1) Disagree
2) Neutral
3) Agree
4) Strongly Agree

9. I have received information from a dental professional about oral health care during my pregnancy
0) Strongly Disagree
1) Disagree
2) Neutral
3) Agree
4) Strongly Agree

10. I have visited a dentist during my pregnancy
0) Strongly Disagree
1) Disagree
2) Neutral
3) Agree
4) Strongly Agree

\section{Abbreviations}

a: Cronbach's alpha; A: Item accepted according to the value obtained from the CVR'; AAPD: American Academy of Pediatric Dentistry; CAPSOM: Maternal Oral Health Knowledge, Attitudes and Practices Questionnaire; (CAPSOM in Spanish); CVI': Content Validity Index; CVR': Content validity ratio; d: Item discrimination level; D: Item difficulty index; ENES: National School of Higher Studies, Leon Unit (ENES in Spanish); KAP: Knowledge, attitudes and practices; KMO: Kaiser-Meyer-Olkin test; R: Item rejected according to the value obtained from the CVR'; Total D: Average difficulty index of the item; UNAM: National Autonomous University of Mexico (UNAM in Spanish.

Acknowledgements

We recognize the support of the followings programs and persons: The Support Program for Research and Technological Innovation Projects (PAPIIT in Spanish) to project IN308920 "Impact of an Educational Program Based on Motivational Interviews on Oral Health Knowledge, Attitudes, and Behaviors in the Mother-Infant Dyad"; National Council of Science and Technology 
(CONACyT in Spanish CVU 547426); Programa de Maestría y Doctorado en Ciencias Médicas, Odontológicas y de la Salud (Student: María de los Ángeles Ramírez Trujillo 300257423); and T. S. Lucia Cuevas Martínez responsible of "Club de embarazadas", CAISES León.

\section{Authors' contributions}

RT: supported during the conceptualization of the paper, collected the information, analysed the data, and wrote the main manuscript. W: conceptualized the project and supported with the analysis of the information and collaborated with the main manuscript. AD: supported with the collection and analysis of the data. FH: Drafted the work or substantively revised it. FS: Gave theoretical support during the implementation of the strategy and collaborated with the manuscript. GC: Drafted the work or substantively revised it. All authors read and approved the final manuscript.

\section{Funding}

The design of the study, collection, analysis and interpretation of data was supported by the Support Program for Research and Technological Innovation Projects (PAPIIT in Spanish) to project IN308920"Impact of an Educational Program Based on Motivational Interviews on Oral Health Knowledge, Attitudes, and Behaviors in the Mother-Infant Dyad"; National Council of Science and Technology (CONACYT in Spanish CVU 547426); and Programa de Maestría y Doctorado en Ciencias Médicas, Odontológicas y de la Salud (Student: María de los Ángeles Ramírez Trujillo 300257423).

\section{Availability of data and materials}

The datasets used and/or analyzed during the current study are available from the corresponding author on reasonable request.

\section{Declarations}

\section{Ethics approval and consent to participate}

The research protocol was approved by the Research Ethics Commission of the National School of Higher Studies (ENES), Leon Unit, of the National Autonomous University of Mexico (UNAM) (CEI.18_013_S1). The participants were informed about the study and that participation in it is voluntary. In addition, information was provided about the positive ethical vote on this survey. A signed declaration of consent was obtained and confirmed verbally. Participants who did not want to participate in the study refused to sign the declaration of consent. The ethics committee approved the method of obtaining consent.

\section{Consent for publication}

Not applicable.

\section{Competing interests}

The author(s) declare(s) that they have no competing interests.

\section{Author details}

'Department of Public Health, National School of Higher Studies, Leon Unit, National Autonomus University of Mexico (UNAM), Blvd. UNAM \#2011, Predio El Saucillo y El Potrero, Comunidad de los Tepetates, 37684 León, Guanajuato, México. ${ }^{2}$ Grupo Hospitalar Conceição (GHC), Porto Alegre, Brazil. ${ }^{3}$ Laboratory of Oral Pathology, Posgratuate and Research Division, Dental School, National Autonomus University of Mexico, México City, México.

\section{Received: 2 July 2021 Accepted: 6 October 2021}

\section{Published online: 30 October 2021}

\section{References}

1. Tullo E, Lerea MJ, González R, Galeano J, Insfrán MD, Muñoz M, Aragón M, Sanhueza A. Desigualdades sanitarias y sociales en la salud materna y del niño en Paraguay. Rev Panam Salud Publica. 2020; 44: e107. https://doi. org/10.26633/RPSP.2020.107.

2. Abanto J, Carvalho TS, Mendes FM, Wanderley MT, Bönecker M, Raggio DP. Impact of oral diseases and disorders on oral health-related quality of life of preschool children. Community Dent Oral Epidemiol. 2011;39:105-14.
3. Vivares-Builes A, Rangel-Rincón L, Botero J, Agudelo-Suárez A. Gaps in knowledge about the association between maternal periodontitis and adverse obstetric outcomes: an umbrella review. J Evid Base Dent Pract. 2018;18:1-27.

4. Thomas N, Middleton P, Crowther C. Oral and dental health care practices in pregnant women in Australia: a postnatal survey. BMC Pregnancy Childbirth. 2008;21(8):13. https://doi.org/10.1186/1471-2393-8-13.

5. El-Mahdi I, Mudawi A, Ghandour I. Oral health status, knowledge and practice among pregnant women attending Omdurman maternity hospital. Sudan EMHJ. 2016;22(11):802-9.

6. Zhong C, Ma K, Wong Y, So Y, Lee P, Yang Y. Oral health knowledge of pregnant women on pregnancy gingivitis and children's oral health. $J$ Clin Pediatric Dentistry. 2015;39(2):105-8.

7. Gaszyńska E, Klepacz-Szewczyk J, Trafalska E, Garus-Pakowska A, Szatko F. Dental awareness and oral health of pregnant women in Poland. Int J Occup Med Environ Health. 2015;28(3):603-11.

8. American Academy of Pediatric Dentistry. Policy on early childhood caries (ECC): unique challenges and treatment options. Oral Health Polices Ref Manual. 2016;39(6):62-3.

9. Pantano M, Abanto J, Matijasevich A, Augusto-Cardoso M. Primeiros 1.000 dias de vida. Rev Assoc Paul Cir Dent. 2018;72(3):490-4.

10. Bamanikar S, Kok KL. Knowledge, attitude and practice of oral and dental healthcare in pregnant women. Oman Med J. 2013;28(4):288-91.

11. Gupta S, Jain A, Mohan S, Bhaskar N, Walia P. Comparative evaluation of oral health knowledge, practices and attitude of pregnant and nonpregnant women, and their awareness regarding adverse pregnancy outcomes. J Clin Diagn Res. 2015;9(11):26-32.

12. Agrawal N, Gupta N, Tewari R, Garg A, Yadav P. Knowledge, attitude and practice of oral health care in pregnant women in North India- a cross sectional survey. Univ J Dent Scie. 2017;3(1):22-5.

13. Hullah E, Turok Y, Nauta M, Yoong W. Self-reported oral hygiene habits, dental attendance and attitudes to dentistry during pregnancy in a sample of immigrant women in North London. Arch Gynecol Obstet. 2008;277:405-9.

14. Boggess K, Urlaub D, Moos MK, Polinkovsky M, El-Khorazaty J, Lorenz C. Knowledge and beliefs regarding oral health among pregnant women. J Am Dent Assoc. 2011;142(11):1275-82.

15. Boggess K, Urlaub D, Massey K, Moos MK, Matheson M, Lorenz C. Oral hygiene practices and dental service utilization among pregnant women. J Am Dent Assoc. 2010;141(5):553-61.

16. Özen B, Özer L, Başak F, Altun C, Açıkel C. Turkish women's self-reported knowledge and behavior towards oral health during pregnancy. Med Princ Pract. 2012;21:318-22.

17. Chacko V, Shenoy R, Prasy H, Agarwal S. Self-reported awareness of oral health and infant oral health among pregnant women in mangalore, india - a prenatal survey. Int J Health Rehabil Sci. 2013;2(2):109-15.

18. Keirse M, Plutzer K. Women's attitudes to and perceptions of oral health and dental care during pregnancy. J Perinat Med. 2010;38:3-8.

19. Finlayson T, Gupta A, Ramos-Gomez F. Prenatal maternal factors, intergenerational transmission of disease, and child oral health outcomes. Dent Clin N Am. 2017;61:483-518.

20. Fisher-Owens S, Gansky S, Platt L, Weintraub J, Soobader M, Bramlett M, Newacheck P. Influences on children's oral health: a conceptual model. Pediatrics. 2007;120(3):e510-20.

21. Wagner Y, Heinrich-Weltzien R. Risk factors for dental problems: recommendations for oral health in infancy. Early Human Dev. 2017;114:16-21.

22. American Academy of Pediatric Dentistry. Policy on social determinants of children's oral health and health disparities. Ref Manual. 2017;40(6):23-6.

23. Kline RB. Principles and practice of structural equation modeling. 2 nd ed. New York: The Guilford Press; 2005.

24. Tristán LA. Modificación al modelo de Lawshe para el dictamen cuantitativo de la validez de contenido de un instrumento objetivo. Avances en Medición. 2008;6:37-48.

25. Kerlinger $\mathrm{F}$, Lee $\mathrm{H}$. Investigación del comportamiento, 4th edition. México: McGraw Hill/Interamericana; 2002.

26. Cohen-Swerdlik. Psychological testing and assessment: an introduction to tests and measurement, 7th edition. New York: McGrawHill; 2010.

27. Pere F, Anguiano-Carrasco C. El análisis factorial como técnica de investigación en psicología. Papeles del Psicólogo. 2010;31(1):18-33. 
28. Naavaal S, Brickhouse T, Hafidh S, Smith K. Factors associated with preventive dental visits before and during pregnancy. J Womens Health (Larchmt). 2019;28(12):1670-8.

29. Detman L, Cottrell B, Denis-Luque M. Exploring dental care misconceptions and barriers in pregnancy. Birth. 2010;37(4):318-24

30. Dinas K, Achyropoulos V, Hatzipantelis E, Mavromatidis G, Zepiridis L, Theodoridis T, Dovas D, Tamtanasis T, Goutzioulis F, Bontis J. Pregnancy and oral health: utilization of dental services during pregnancy in northern Greece. Acta Obstet Gynecol Scand. 2007:86(8):938-44.

31. Jessani A, Laronde D, Mathu-Muju K, Brondani M. Self-perceived oral health and use of dental services by pregnant women in surrey, British Columbia. J Can Dent Assoc. 2016;82:28.

32. Nunnally J. Teoría Psicométrica. México: McGraw-Hill; 1995.

33. Streiner D. Starting at the beginning: an introduction to coefficient alpha and internal consistency. J Pers Assess. 2003;80(1):99-103.

34. Abramson JH. Métodos de estudio en medicina comunitaria: una introducción a los estudios epidemiológicos y de evaluación. Madrid: Ediciones Díaz de Santos; 1990.

35. Grime M, Wright G. Delphi method. Wiley StatsRef: statistics reference. 2016. https://doi.org/10.1002/9781118445112.stat07879.

36. Kleinbaum D, Kupper L, Morgenstern H. Epidemiologic research. principles and quantitative methods. 1982; New York: Van Nostrand Reinhold; 1982.
37. Rush B, Rankin D, White B. The impact of item-writing flaws and item complexity on examination item difficulty and discrimination value. BMC Med Educ. 2016;16(1):250

38. Villanueva-Vilchis MC, Wintergerst A, Borges-Yañez SA. Toward a comprehensive instrument of oral health literacy in Spanish. J Health Commun. 2015;20(8):930-7.

39. Toscano-Garcia I, Luengo-Fereira JA, Anaya-Álvarez M, Carlos-Medrano LE, López-Ávila L, Márquez-Sánchez S. Evaluación del nivel de conocimientos sobre salud oral en embarazadas que acuden al Hospital de la Mujer Zacatecas - México. Multidiscip Heal Res. 2016;1(3):83-90.

40. Fuentes Fernández R, Oporto Venegas G, Alarcón AM, Bustos Medina L, Prieto Gómez R, Rico WH. Opiniones y creencias de embarazadas en control prenatal relacionadas con salud oral y embarazo. Av Odontoestomatol. 2009;25(3):147-54.

41. Arias Altamirano CA, Orozco F. Conocimientos, actitudes y prácticas de embarazadas en control prenatal relacionadas con salud oral y embarazo, de mujeres que acuden a consulta externa del Hospital Gíneco Obstétrico Isidro Ayora. Odontolnvestigación. 2017;3(1):1-17.

\section{Publisher's Note}

Springer Nature remains neutral with regard to jurisdictional claims in published maps and institutional affiliations.
Ready to submit your research? Choose BMC and benefit from:

- fast, convenient online submission

- thorough peer review by experienced researchers in your field

- rapid publication on acceptance

- support for research data, including large and complex data types

- gold Open Access which fosters wider collaboration and increased citations

- maximum visibility for your research: over $100 \mathrm{M}$ website views per year

At BMC, research is always in progress.

Learn more biomedcentral.com/submissions 